\title{
Design Optimization of a Refrigerant-Cooling Thermal Management System for the Battery in Electric Vehicles
}

\author{
Seonggi Park ${ }^{1}$, Dong Soo Jang ${ }^{1}$, DongChan Lee ${ }^{1}$, Wonseok Yang1, Yongchan Kim² \\ ${ }^{1}$ Graduate School of Mechanical Engineering, Korea University \\ 145, Anam-Ro, Seongbuk-Gu, Seoul, Korea \\ jingjinge1@korea.ac.kr; nicebb0y@korea.ac.kr; ldc1120@korea.ac.kr; yws1561@naver.com \\ ${ }^{2}$ Department of Mechanical Engineering, Korea University \\ 145, Anam-Ro, Seongbuk-Gu, Seoul, Korea \\ yongckim@korea.ac.kr
}

\section{Extended Abstract}

As Li-ion cells are widely used for power source of electric vehicles, thermal management of batteries become an important issue. The large energy capacity and compactness of the cells cause heat accumulation in the battery pack. Excessively high temperature and uneven temperature distribution in the battery degrade the performance and reduce the cycle life of the cells. Many kinds of thermal management system are developed and used to cool down the battery during the operation process. The conventional air-cooling system is low cost and easy to fabricate, but it shows insufficient cooling performance in abuse conditions with high discharge rate and high ambient temperature, which is due to low heat transfer coefficient and small thermal capacity of the air. As an alternative system of air-cooling, two-phase cooling systems are considered because latent heat cooling has very large thermal capacity at a constant temperature. As a solid-toliquid phase change, PCMs are used for thermal management of batteries in many studies [1-2]. Refrigerants are also used in some systems, as a liquid-to-vapor phase change [3].

In this paper, a two-phase cooling system using R-134a as a coolant is modelled. A rectangular type Li-ion cell with large capacity is applied, and 10 to 20 numbers of cells form a module. Micro-channel heat sink is attached on the bottom surface of the module and absorbs the heat from the module. The effects of the refrigerant temperature and mass flow rate on the cooling performance are investigated using a 3-D transient numerical model. The discharge rate and the ambient temperature vary according to operating conditions, and the maximum temperature of the battery module and the maximum temperature difference in the module are calculated to evaluate thermal performance.

In mild operating condition when the discharge rate is $1 \mathrm{C}$ and the ambient temperature is $20-25^{\circ} \mathrm{C}$, the maximum temperature during the discharge process is below $30^{\circ} \mathrm{C}$ and the maximum temperature difference in the module is within the allowable range of $5^{\circ} \mathrm{C}$. However, in abuse condition of a discharge rate of $2 \mathrm{C}$ and an ambient temperature of $30^{\circ} \mathrm{C}$, the temperature difference exceeds the range of $5^{\circ} \mathrm{C}$ at the end of discharge. The decrease of the refrigerant temperature and increase of the mass flow rate drop the maximum temperature of the module, but increase the temperature difference in the module. By analysing this trade-off characteristic of the maximum temperature and temperature difference, the temperature and mass flow rate of the refrigerant are optimized in each specific operating condition. Finally, an improved cooling system which combines the refrigerant-cooling and forced air-cooling is suggested and the enhancement of the cooling performance is also investigated. In the newly designed system, the refrigerant-cooling plays a role in dropping the maximum temperature of the module while the forced air-cooling enhances the heat transfer on the module surface and reduces the temperature difference significantly.

\section{References}

[1] S. Al-Hallaj and J. R. Selman, "Thermal modelling of secondary lithium batteries for electric vehicle/hybrid electric vehicle applications,” Journal of Power Sources, vol. 110, pp. 341-348, 2002. 
[2] R. Sabbah et al., "Active (air-cooled) vs. passive (phase change material) thermal management of high power lithium-ion packs: Limitation of temperature rise and uniformity of temperature distribution," Journal of Power Sources, vol. 182, pp. 630-638, 2008.

[3] H. S. Hamut et al., "Performance assessment of thermal management systems for electric and hybrid electric vehicles," International Journal of Energy Research, vol. 37, pp. 1-12, 2013. 